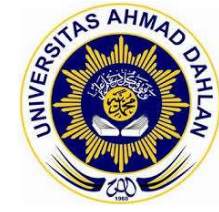

BERKALA FISIKA INDONESIA Jurnal IImiah Fisika, Pembelajaran dan Aplikasinya

http://journal.uad.ac.id/index.php/BFl/index 2085-0409 (Print) |2550-0465 (online)

\title{
Studi hukum Hagen-Poiseuille dalam menentukan diameter terbaik pipa kapiler pada eksperimen penentuan viskositas zat cair
}

\author{
Okimustava ${ }^{1 *}$, Elvi Nurridho Khasanah ${ }^{2}$, Fitri Nur Hikmah ${ }^{3}$, Jamaludin Djumati ${ }^{4}$, Lia Adini ${ }^{5}$ \\ 1,2 Pendidikan Fisika, Fakultas Keguruan dan IImu Pendidikan, Universitas Ahmad Dahlan, Indonesia \\ ${ }^{3}$ Tadris Fisika, Fakultas Tarbiyah dan Keguruan, Universitas Islam Negeri Antasari, Indonesia \\ ${ }^{4}$ SMA Negeri 2 Tidore Kepulauan, Indonesia \\ 5 SMPN 33 Bandar Lampung, Indonesia \\ Email: okimustava@pfis.uad.ac.id* \\ * Penulis korespondensi
}

\begin{tabular}{l}
\hline Informasi artikel \\
\hline Sejarah artikel: \\
Dikirim \\
Revisi \\
Diterima \\
\hline
\end{tabular}

\section{Kata kunci:}

Gliserin

Hukum Hagen-Poiseuille

Logger Pro

Oli SAE 10W-30

Viskositas

\begin{abstract}
ABSTRAK
Studi hukum hagen-poiseuille dalam menentukan diameter terbaik pipa kapiler pada eksperimen penentuan viskositas zat cair telah dilakukan dengan cairan berupa air, gliserin dan oli. Tujuan dari penelitian ini adalah menegtahui diameter pipa kapiler yang paling baik dalam proses penentuan nilai viscositas zat cair menggunakan hukum Hagen-Poisseuille. Eksperimen ini dirancang menggunakan hukum Hagen-Poiseuille pada beberapa diameter pipa kapiler yang berbeda, yaitu sebesar $1 \mathrm{~mm}, 2 \mathrm{~mm}$, dan $3 \mathrm{~mm}$. Proses pengambilan data menggunakan batuan interface Logger Pro dan sensor gaya serta analisis data menggunakan bantuan software Logger Pro. Jenis bahan yang digunakan yaitu air, gliserin dan oli SAE 10W-30. Hasil penelitian menunjukkan bahwa nilai viscositas zat cair yang terbaik dan sesuai dengan acuan yaitu pada diametet pipa $3 \mathrm{~mm}$ dengan nilai viscositas masinng-masing adalah air $1.05 \pm 0.13 \mathrm{mPa}$.s yang sesuai dengan acuan yaitu $1,002 \mathrm{mPa} . \mathrm{S}$, Gliserin dengan nilai viscositas $589.79 \pm 99.99 \mathrm{mPa}$.S yang sesuai dengan acuan yaitu 612 mPa.s dan oli SAE 10W-30 yaitu 73.18 $9.92 \mathrm{mPa}$.S yang sesuai dengan acuan yaitu 76,8 mPa.s. sedangkan pada diameter $1 \mathrm{~mm}$ dan $2 \mathrm{~mm}$ nilai viscositasnya tidak sesuai dengan acuan, hal ini disebabkan karen nilai viscositas zat cair tersebut terlalu besar sehingga sulit mengalir pada pipa dengan diameter kecil.
\end{abstract}

This is an open access article under the CC-BY-SA license

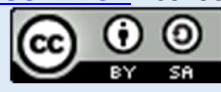

\section{Keywords:}

Glycerin

Hagen-Poiseuille law

Logger Pro

SAE 10 W-30 oil

Viscosity

\section{ABSTRACT}

Study of Hagen-Poiseuille law in determining the best diameter of capillary tubes in experiments to determine the viscosity of a liquid. The study of the Hagen-Poiseuille law in determining the best diameter of the capillary tube in the experiment to determine the viscosity of a liquid has been carried out with liquids in the form of water, glycerin and oil. The purpose of this study was to determine the best capillary tube diameter in the process of determining the viscosity value of a liquid using the Hagen-Poisseuille law. This experiment was designed using the Hagen-Poiseuille law on several different capillary tube diameters, namely $1 \mathrm{~mm}, 2 \mathrm{~mm}$, and $3 \mathrm{~mm}$. The data retrieval process uses the Logger Pro interface rock and force sensors and data analysis using the Logger Pro software. The types of materials used are water, glycerin and SAE $10 \mathrm{~W}-30$ oil. The results showed that the best liquid viscosity value and by the reference is at $3 \mathrm{~mm}$ pipe diameter with a viscosity value of $1.05 \pm 0.13 \mathrm{mPa}$.s respectively, which is by the reference, namely $1.002 \mathrm{mPa}$.S, glycerin with a viscosity value of $589.79 \pm 99.99 \mathrm{mPa}$.S according to the reference, namely $612 \mathrm{mPa}$.s and SAE $10 \mathrm{~W}-30$ oil, namely $73.18 \pm 9.92 \mathrm{mPa}$.S which is by the reference, namely $76.8 \mathrm{mPa}$.s. The viscosity values are not by the reference at the diameter of $1 \mathrm{~mm}$ and $2 \mathrm{~mm}$. The viscosity value of the liquid is too large, so it is difficult to flow in pipes with small diameters.

How to Cite: 
Okimustava, Khasanah, E. N., Hikmah, F. N., Djumati, J., \& Adini, L. (2020). Studi Hukum Hagen-

Poiseuille dalam Menentukan Diameter Terbaik Pipa Kapiler pada Eksperimen Penentuan Viskositas

Zat Cair. Berkala Fisika Indonesia: Jurnal Ilmiah Fisika, Pembelajaran dan Aplikasinya, 11(1), 18-23.

\section{Pendahuluan}

Zat cair merupakan molekul yang tersusun secara acak dan melekat bersama-sama akibat suatu gaya kohesi yang lemah karena gaya yang dikerjakan oleh dinding-dinding permukaan (Serwey \& Jewet, 2009). Setiap zat cair memiliki karakteristik viskositas yang berbeda. Saat ini pengukuran kekentalan atau viskositas suatu zat cair sangat penting dilakukan dalam berbagai proses industri seperti pembentukan polimer, pembuatan pernis, kosmetik, bahkan dalam produk makanan. Viskositas setiap zat cair berbeda dan dinyatakan secara kuantitatif oleh koefisien viskositas $\eta$ (Giancoli, 2001). Penentuan nilai viskositas sangat diperlukan dalam penentuan sifat fisik suatu zat cair. Koefisien viskositas timbul dari gesekan internal zat cair. Gesekan yang timbul berhubungan dengan hambatan zat cair ketika mengalir. Beberapa zat cair dapat mengalir dengan cepat dan mengalir dengan lambat. Jika nilai koefisien viskositas semakin besar, maka semakin kental pula zat cair tersebut (Salim, 2014). Kecenderungan untuk melawan aliran terjadi karena resistensi suatu zat cair yang mengalami perubahan bentuk bila zat cair tersebut dikenai gaya (Yunita, 2018). Hambatan terhadap gerak relatif antara lapisanlapisan zat cair berhubungan dengan gaya kohesi antar molekul (Firdaus, 2017). Gaya kohesi antar molekul zat cair menghasilkan suatu viskositas. Zat cair yang lebih kental membutuhkan gaya yang lebih besar sedangkan zat cair yang kurang kental membutuhkan gaya yang lebih kecil (Lubis, 2018; Ningrum \& Toifur, 2014). Terdapat dua jenis viskositas yaitu viskositas dinamis dan viskositas kinematis. Pada viskositas kinematis, viskositas dinamis dibandingkan terhadap massa jenis zat cair. Sedangkan viskositas dinamis memiliki kecenderungan melawan aliran zat cair (Ardiansyah, 2017). Selain itu, nilai viskositas juga dipengaruhi suhu. Jika suhu suatu zat cair dinaikkan maka nilai viskositas akan berkurang (Budianto, 2008).

Beberapa teknik untuk menghitung viskositas telah digunakan, salah satunya dengan mengamati aliran cairan ke saluran kapiler (Armitage, 1983). Karakteristik pipa kapiler, viskositas zat cair, dan tekanan hidrostatis mempengaruhi laju aliran zat cair. Laju aliran zat cair dapat diketahui dengan mengikuti Hukum Hagen-Poiseuille pada persamaan (1). Kecepatan rata-rata $V$ untuk aliran laminer dari sebuah cairan viskos pada pipa dengan panjang $L$ dan radius $r$ diberikan oleh sebuah persamaan hubungan Hagen-Poiseuille (Nauenberg, 2014),

$$
V=\frac{\pi R^{4} \Delta P}{8 \eta L}
$$

dengan $V$ merupakan laju aliran, $R$ merupakan jari-jari pipa kapiler, $\Delta P$ merupakan perbedaan tekanan pada kedua ujung pipa, $\eta$ merupakan viskositas zat cair dan $L$ merupakan panjang pipa kapiler. (Sianoudis \& Drakaki, 2008).

Untuk aliran laminer cairan yang tak terkompresi melewati pipa dengan jari-jari $r$, maka nilai tegangan menurun sebesar $\Delta P_{c}$ diakibatkan oleh pengurangan kekentalan yang melewati pipa dengan panjang $L_{c}$ diberikan oleh hukum Hagen-Poiseuille.

$$
\Delta P_{c}=\frac{8 \eta L_{c}}{r^{2}} u
$$

dengan $\eta$ merupakan viskositas dinamis cairan dan $u$ adalah kecepatan aliran rata-rata.

Hambatan aliran cairan bisa ditentukan dengan apparatus sederhana terdiri dari tangki dengan luas penampang konstan $S$, cairan akan keluar dari tangki melewati pipa kapiler yang terhubung tegak lurus akibat gaya gravitasi dengan kedalaman $h$ di bawah permukaan cairan di dalam tangki. Cairan memasuki pipa kapiler pada tekanan tinggi akibat pengaruh gaya berat cairan di atasnya, sementara tekanan ujung pipa yang lain hanya di bawah tekanan atmosfer. Ketika salah satu ujung pipa berada pada kedalaman $h$ di bawah permukaan tabung cairan yang vertikal dan terbuka dengan massa jenis cairan $\rho$ dan luas penampang $A$, perbedaan tekanan di ujung salah satu pipa terbuka pada tekanan atmosfir adalah sebesar $\rho g h$ (Fairman and Walkiewicz, 2003). 
Oleh karena itu, tegangan yang turun melewati pipa kapiler merupakan tegangan hidrostatis yang meluruh sebagaimana cairan mengalir.

$$
\Delta P_{c}(t)=\rho g h(t)=\frac{m(t) g}{S}
$$

dengan $g$ adalah percepatan gravitasi dan $m(t)$ adalah massa cairan pada tangki pada waktu $t$. untuk aliran yang kira-kira tetap, $u$ dapat dinyatakan dalam bentuk laju pengurangan massa (Adini dan okimustava; 2017).

$$
u=-\frac{1}{\pi r^{2} \rho} \frac{d m}{d t}
$$

dengan tanda negatif berarti massa cairan mengalami penurunan. Dalam hal ini, persamaan (4) menghasilkan:

$$
m(t)=-\frac{8 \eta L_{c} S}{\pi r^{4} \rho g} \frac{d m}{d t}
$$

dengan $m_{0}$ adalah massa rujukan pada saat $t=0$.

Untuk aliran yang tak begitu tetap, distribusi tekanan pada sistem dipengaruhi oleh persamaan Bernoulli-Poiseuille.

$$
\Delta P_{c}=\rho g\left(h+L_{c}\right)+\frac{1}{2} \rho u_{t}^{2}-\xi \rho u_{c}^{2}
$$

dengan dengan menggunakan persamaan (5) dan (6) dapat kembali ditulis sebagai:

$$
m+\rho L_{c} S=-\tau \frac{d m}{d t}+\alpha\left(\frac{d m}{d t}\right)^{2}
$$

Dengan cara yang sama, untuk pipa kapiler yang terhubung secara horizontal pada tangki, dapat diperoleh

$$
m(t)=\frac{m_{0} \exp \left(-\frac{t}{\tau}\right)}{\left\{1-m_{0}\left(\frac{\alpha}{\tau^{2}}\right)\right\}\left\{1-\exp \left(-\frac{t}{\tau}\right)\right\}}
$$

Keuntungan persamaan (8) adalah ketetapan matematisnya dimodifikasi oleh koreksi energi kinetik yang direduksi oleh persamaan (1) sebesar $\alpha \rightarrow 0$ (Digilov, 2005).

Adapun persamaan (8) dapat dituliskan ke dalam bentuk persamaan

$$
m(t)=\frac{(A+B) \exp \left(-\frac{t}{C}\right)}{\left\{1-\left((A+B)\left(\frac{D}{C^{2}}\right)\right\}\left\{1-\exp \left(-\frac{t}{C}\right)\right\}\right.}-B
$$

dengan tujuannya adalah untuk mempermudah persamaan yang akan digunakan saat fitting data pada Logger Pro. Untuk ralat viskositas digunakan analisis regresi linear dengan variasi massa zat cair (Adini dan Okimustava; 2017).

Perkembangan teknologi yang semakin canggih mendorong setiap ilmuan untuk mengintegrasikan ke dalam kegiatan eksperimen sehingga eksperimen yang dilakukan menjadi lebih sederhana. Penggunaan berbagai software seperti Tracker dapat digunakan untuk analisis video dan dikembangkan untuk menentukan kecepatan terminal sehingga dapat diketahui viskositas suatu zat cair (Setiawati \& Radiyono, 2017). Paket perangkat lunak komersial seperti Vernier yang Logger Pro dan Coach CMA telah dikembangkan (Hantoro \& Suharno, 2014). Eksperimen ini menggunakan variasi yang berbeda dengan eksperimen terdahulu. Diameter tabung pipa kapiler divariasikan dan tidak mengubah zat cair yang digunakan.

Percobaan penentuan nilai viskositas dengan variasi diameter pipa kapiler menggunakan hukum Hagen-Poiseuille berbasis Logger Pro merupakan penerapan dari percobaan yang dilakukan oleh Torricelli dimana air muncul dari lubang dengan kelajuan yang sama jika air itu jatuh bebas sejauh $h$ (Tipler, 1991). Perbedaan diameter mempengaruhi nilai viskositas yang dihasilkan semakin kecil 
diameter pipa kapiler yang digunakan nilai viskositas yang dihasilkan semakin mendekati nilai viksositas teori. Perbandingan penggunaan diameter dalam penentuan nilai viskositas dapat dilihat dari grafik. Jadi, tujuan penelitian ini untuk mengetahui pengaruh diameter pipa kapiler terhadap nilai viskositas yang dihasilkan.

\section{Metode}

Penentuan nilai viskositas menggunakan hukum Hagen-Poiseuille dengan variasi diameter pipa kapiler berbasis software Logger Pro. Bahan yang digunakan yaitu air, gliserin dan oli SAE 10W- 30. Apparatus dari penelitian ini terdiri dari statif dengan tinggi $\pm 75 \mathrm{~cm}$, tabung akrilik dengan diameter $3,4 \mathrm{~cm}$ dan panjang $40 \mathrm{~cm}$, tutup botol dengan diameter yang berbeda-beda yaitu $1 \mathrm{~mm}, 2 \mathrm{~mm}$ dan 3 $\mathrm{mm}$, sensor gaya, laptop dan gelas ukur $50 \mathrm{ml}$. Tabung yang digunakan yaitu jenis tabung kaca pyrex $250 \mathrm{ml}$. Pada gambar 1 ditunjukkan Sensor gaya yang dipasang pada statif kemudian dihubungkan ke interface dan disambungkan ke laptop yang sudah terinstall sofware Logger Pro. Tabung akrilik diisi dengan zat cair yang akan diukur viskositasnya. Posisi lubang kecil pipa kapiler dalam keadaan ditutup.

Sebelum dimulai perekaman video pada software Logger Pro, tabung diisi dengan zat cair yang akan di ukur nilai viskositas sebanyak $20 \mathrm{ml}$ dengan pengambialn data pertama menggunakan diameter pipa kapiler $1 \mathrm{~mm}$, setiap diameter dilakukan 3 kali pengambilan data untuk setiap cairan, pengambilan data dimulai dari saat pertama cairan menetes hingga cairan dalam tabung akrilik habis atau berhenti menetes. Hal yang sama juga digunakan untuk pengambilan data pada jenis bahan yang lainnya yaitu gliserin dan Oli SAE 10W-30.

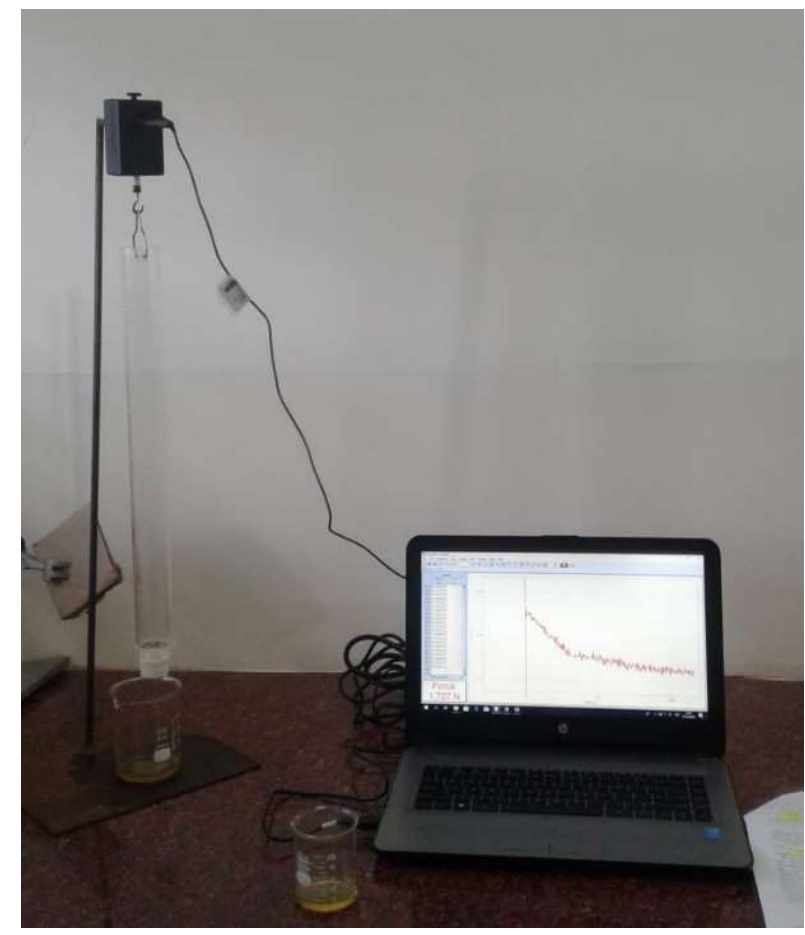

Gambar 1. Apparatus pengukuran nilai viskositas

\section{Hasil dan Pembahasan}

Hasil penelitian yang dilakukan berdasarkan langkah kerja yang sesuai dengan metode yang digunakan maka dapat diperoleh hasil seperti dalam Gambar 2 (air), Gambar 3 (Gliserin), dan Gambar 4 (Oli SAE 10W-30). Gambar 2 menunjukkan grafik viskositas air pada pipa dengan diameter $3 \mathrm{~mm}$. 


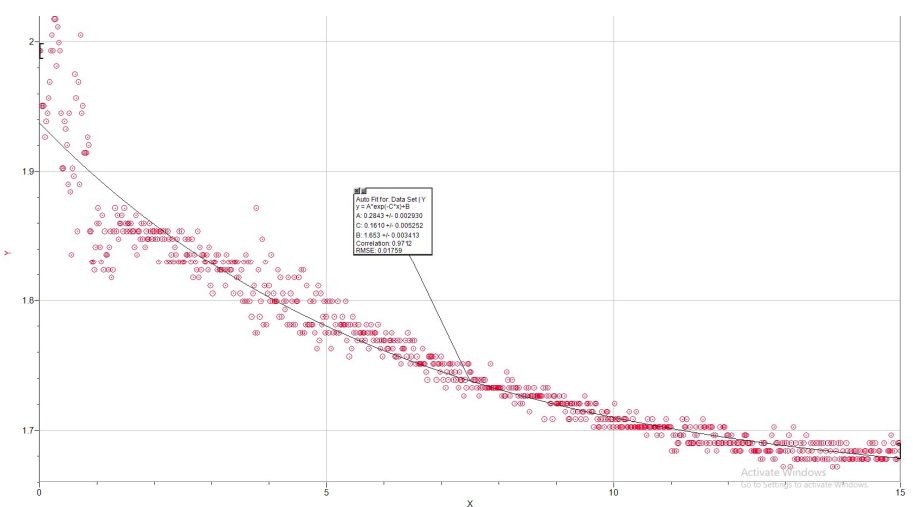

Gambar 2. Grafik pengambilan data viscositas air pada diameter pipa $3 \mathrm{~mm}$

Gambar 3 menunjukkan grafik viskositas gliserin pada pipa dengan diameter $3 \mathrm{~mm}$.

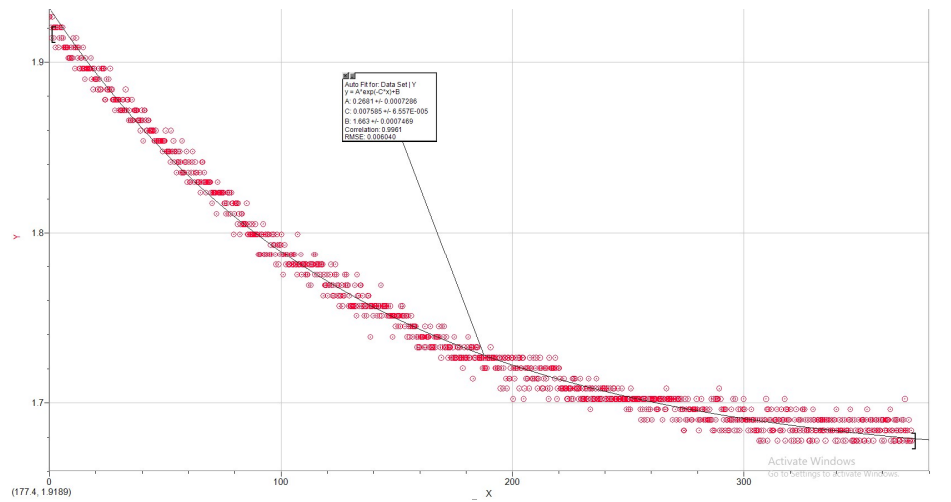

Gambar 3. Grafik pengambilan data viscositas gliserin pada diameter pipa $3 \mathrm{~mm}$

Gambar 4 menunjukkan grafik viskositas Oli SAE 10W-30 terhadap diameter pipa kapiler 3 mm.

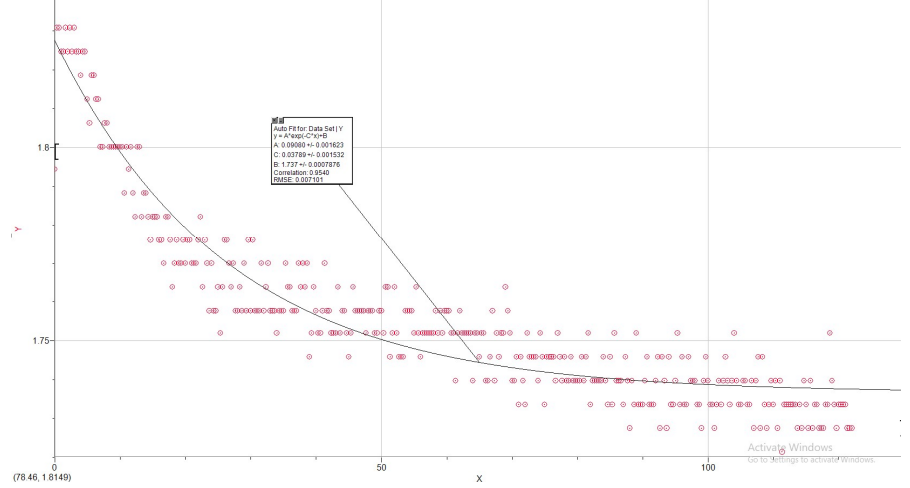

Gambar 4. Grafik pengambilan data viskositas Oli SAE 10W-30 pada diameter pipa $3 \mathrm{~mm}$

Berdasarkan grafik hasil penelitian pada ketiga bahan zat cair dengan volume $20 \mathrm{ml}$ diperoleh informasi yang diringkas dalam Tabel 1 .

Tabel 1. Nilai viskositas cairan pada 3 diameter yang berbeda

\begin{tabular}{clll}
\hline Diameter $(\mathbf{m})$ & \multicolumn{1}{c}{$\begin{array}{c}\text { nilai vikositas air } \\
\text { (mPa.s.) }\end{array}$} & $\begin{array}{c}\text { nilai vikositas gliserin } \\
\text { (mPa.s.) }\end{array}$ & $\begin{array}{c}\text { nilai vikositas oli } \\
\text { (mPa.s.) }\end{array}$ \\
\hline 0.001 & $0.62 \pm 0,14$ & $233.73 \pm 54.99$ & $21.5811 \pm 8.419$ \\
0.002 & $1.29 \pm 0.38$ & $344.51 \pm 99.92$ & $55.0777 \pm 9.21$ \\
0.003 & $1.05 \pm 0.13$ & $589.79 \pm 99.99$ & $73.18 \pm 9.92$ \\
Nilai acuan viscositas & 1,002 & 612 & 76,8 \\
\hline
\end{tabular}


Dari Tabel 1 dapat dilihat bahwa nilai viscositas ketiga bahan yang sesuai dengan acuan hanya pada diameter $3 \mathrm{~mm}$, menunjukkan bahwa pengujian nilai viskositas zat cair yang memiliki viscositas besar sebaiknya menggunakanan diameter pipa kapiler yang besar. Hal ini disebabkan karena zat cair yang memiliki kekentalan tinggi akan sulit mengalir pada pipa kapiler yang memiliki diameter kecil.

\section{Simpulan}

Berdasarkan penelitian yang telah dilakukan dapat disimpulkan bahwa Hasil penelitian menunjukkan bahwa nilai viscositas zat cair yang terbaik dan sesuai dengan acuan yaitu pada diametet pipa $3 \mathrm{~mm}$ dengan nilai viscositas masinng-masing adalah air $1.05 \pm 0.13 \mathrm{mPa}$.s yang sesuai dengan acuan yaitu 1,002 mPa.S, Gliserin dengan nilai viscositas $589.79 \pm 99.99 \mathrm{mPa}$.S yang sesuai dengan acuan yaitu 612 mPa.s dan oli SAE 10W-30 yaitu 73.18 $9.92 \mathrm{mPa}$.S yang sesuai dengan acuan yaitu 76,8 $\mathrm{mPa}$.s. sedangkan pada diameter $1 \mathrm{~mm}$ dan $2 \mathrm{~mm}$ nilai viscositasnya tidak sesuai dengan acuan, hal ini disebabkan karen nilai viscositas zat cair tersebut terlalu besar sehingga sulit mengalir pada pipa dengan diameter kecil.

\section{References}

Adini, L \& Okimustava. (2017). Penggunaan Hukum Hagen-Poiseuille dalam Penentuan Koefisien Viskositas Zat Cair dengan Prinsip Kontrol Berat Berbantuan Software Logger Pro. Jurnal Riset dan Kajian Pendidikan Fisika Vol.4 No.2 Oktober 201.

Ardiansyah, D. (2017). Perancangan dan penerapan sensor kumparan untuk percobaan viskositas dengan metode bola jatuh. Inovasi Fisika Indonesia, 6(1), 5-9.

Armitage, E. (1983). Practical Physics in SI.

Budianto, A. (2008). Metode penentuan koefisien kekentalan zat cair dengan menggunakan regresi linear hukum stokes. In Seminar Nasional IV SDM Teknologi Nuklir, 157-166.

Digilov, R. M. dan M. Reiner. (2005). Weight-Controlled Capillary Viscometer. American Journals of Physics Teacher. 73 (11), November 2005

Fairman S J, Joseph A. Johnson, dan Thomas A. Walkiewicz . (2003). Fluid Flow with Loger Pro. The Physics Teacher. Vol 41. September 2003

Firdaus. (2017). Analisis pola perubahan viskositas minyak goreng. SPEKTRA: Jurnal Kajian Pendidikan Sains, 3(1), 53-62.

Giancoli, D. C. (2001). Fisika edisi kelima jilid 1. Jakarta: Erlangga.

Hantoro, B. B., \& Suharno. (2014). Menyelidiki hubungan kecepatan terminal dan viskositas zat cair dengan video analisis tracker. In Prosiding Pertemuan Ilmiah XXVIII HFI Jateng \& DIY.

Lubis, N. A. (2018). Pengaruh kekentalan cairan terhadap waktu jatuh benda menggunakan falling ball method. FISITEK: Jurnal Ilmu Fisika dan Teknologi, 2(2), 26-32.

Nauenberg, M. (2014). A Paradox with the Hagen-Poiseuille Relation for Viscous Fluid Flow. American Journals of Physics, Vol. 82, No. 1, Januari 2014

Ningrum, R. S. K., \& Toifur, M. (2014). Penentuan viskositas larutan gula menggunaan metode vessel terhubung viscosimeter berbasis video based laboratory dengan software tracker. Jurnal Riset dan Kajian Pendidikan Fisika, 1(2), 57-62.

Salim, M. B. (2014). Mengetahui pengaruh koefisien viskositas akuades terhadap variasi diameter tabung menggunakan adobe audition 1.5. Jurnal Pendidikan Fisika, 2(2), 27-36.

Serwey, R. A., \& Jewet. (2009). Fisika untuk sains dan teknik. Jakarta: Salemba Teknika.

Setiawati, D., \& Radiyono, Y. (2017). Analisis hubungan kecepatan terminal dengan viskositas zat cair menggunakan software tracker. Jurnal Materi dan Pembelajaran Fisika, 7(2), 1-6.

Sianoudis, I. A., \& Drakaki, E. (2008). An approach to Poiseuille's law in an undergraduate laboratory experiment. European Journal of Physics, 29(3), 489-495.

Tipler, P. A. (1991). Fisika untuk sains dan teknik. Jakarta: Erlangga.

Yunita, L. (2018). Studi komparasi penentuan viskositas lumpur pemboran menggunakan marsh funnel dan viscosimeter berbasis video berbantuan software tracker. Jurnal Offshore: Oil, Production Facilities and Renewable Energy, 2(1), 10-19.

p-ISSN 2085-0409

e-ISSN 2550-0465
Berkala Fisika Indonesia : Jurnal IImiah Fisika, Pembelajaran dan Aplikasinya Vol. 11 No. 1, Januari $2020 \mid 18-23$ 